\title{
Customer Involvement in Continuous Deployment: A Systematic Literature Review
}

\author{
Sezin Gizem Yaman ${ }^{1}$, Tanja Sauvola ${ }^{2}$, Leah Riungu-Kalliosaari ${ }^{1}$, Laura Hokkanen ${ }^{3}$, \\ Pasi Kuvaja ${ }^{2}$, Markku Oivo ${ }^{2}$, Tomi Männistö ${ }^{1}$ \\ ${ }^{1}$ Department of Computer Science, University of Helsinki \\ \{sezin.yaman, riungu, tomi.mannisto\} @cs.helsinki.fi \\ ${ }^{2}$ Department of Information Processing Science, University of Oulu \\ \{tanja.sauvola, pasi.kuvaja, markku.oivo\} @oulu.fi \\ ${ }^{3}$ Department of Pervasive Computing, Tampere University of Technology \\ laura.hokkanenetut.fi
}

\begin{abstract}
Context and motivation] In order to build successful software products and services, customer involvement and an understanding of customers' requirements and behaviours during the development process are essential. [Question/Problem] Although continuous deployment is gaining attention in the software industry as an approach for continuously learning from customers, there is no common overview of the topic yet. [Principal ideas/results] To provide a common overview, we conduct a secondary study that explores the state of reported evidence on customer input during continuous deployment in software engineering, including the potential benefits, challenges, methods and tools of the field. [Contribution] We report on a systematic literature review covering 25 primary studies. Our analysis of these studies reveals that although customer involvement in continuous deployment is highly relevant in the software industry today, it has been relatively unexplored in academic research. The field is seen as beneficial, but there are a number of challenges related to it, such as misperceptions among customers. In addition to providing a comprehensive overview of the research field, we clarify the gaps in knowledge that need to be studied further.
\end{abstract}

Keywords: Customer involvement, customer feedback, user involvement, user feedback, continuous deployment, continuous delivery, software development

\section{Introduction}

In today's highly competitive and quickly changing markets, the software intensive industry is evolving towards a value-driven and adaptive real-time business paradigm [1]. Customer involvement in the software development process and an understanding of customers' requirements and behaviours are essential when building successful software products and services. Customer involvement provides an opportunity to enhance product performance based on a better understanding of customers' needs and results in reduced research and development $(\mathrm{R} \& \mathrm{D})$ costs [2]. In many cases,

adfa, p. 1, 2011.

(C) Springer-Verlag Berlin Heidelberg 2011 
customers can be seen as one of the key resources for product development, as they often gain deep knowledge and experience by using the product or service. However, customers' requirements might change very rapidly, and they are often difficult to identify. This may lead to a situation where R\&D spends time and effort on developing product functionalities that do not add value for customers.

Requirements Engineering (RE) is one of the most crucial processes in software development aiming at maximizing the value of a release of software while accommodating a collaborative approach throughout the product development where multiple stakeholder perspectives are involved [3,4]. Likewise, allowing for more flexible ways of working with an emphasis on customer collaboration, responding to change and speed of development, agile methods help companies to address many of the problems associated with traditional software development [5]. Recent studies show that even though the ways to learn about customers are increasing, software companies often find it challenging to obtain timely and accurate feedback from customers to support R\&D decision-making processes continuously [6, 7]. In agile methodologies and new approaches such as continuous deployment (CD) and rapid feature validation, the customer is seen as a way to improve decision-making and R\&D efficiency. Olsson et al. [8] defined CD as 'the ability to deliver software functionality frequently to the customer and subsequently, the ability to continuously learn from real-time customer usage of software'. CD-related research is also emerging in literature in the field of software engineering [9]. However, there is no common understanding of customer involvement practices in CD that would guide both researchers and practitioners.

Customer involvement is an abstract concept that refers to the ways in which the customer plays a role in the software development process and the extent of the customer's participation [2]. In general, customer involvement is studied widely in areas such as participatory design, user-centric design, usability engineering and requirements engineering [10]. In this paper, customer involvement refers to the process by which end users or customers actively or unintentionally become part of any stage of the software development life cycle. The terms 'user(s)' and 'customer(s)' are used interchangeably depending on the context. Likewise, we consider CD and continuous delivery to be synonyms.

Although CD is gaining attention in the software industry, there is no systematic literature review that provides an overview of the topic within the software engineering field. Thus, we conducted a systematic literature review (SLR) of customer involvement in $\mathrm{CD}$, where the first four authors of this paper conducted the research and rest of the authors reviewed the work. The need for this SLR emerged in the context of a large Finnish research program ${ }^{1}$ that aimed to enhance Finnish ICT companies' ability to deliver value in real-time. The main objective of this study is to discover current research on customer involvement in $\mathrm{CD}$, provide a structured body of knowledge on the research area and clarify the underlying factors related to customer input during CD. We take established RE activities into account throughout the paper to see how customer involvement in $\mathrm{CD}$ is in line with them. Our objectives for the

1 Need for Speed; http://www.n4s.fi/en/ 
study are expressed in the form of research questions, which are presented in Section 2.1.The rest of the paper is structured as follows. In Section 2, we describe our research questions and research methodology. In Section 3, we present the results of our literature review together with discussion. Next, in Section 4, we address limitations and threats to our study and the countermeasures that were taken to minimise their effects. Finally, in Section 5, we conclude the study and provide recommendations for future works.

\section{Research Method}

In this study, we followed the guidelines for SLRs established by Kitchenham and Charters [11].

An SLR consists of three phases: planning, conducting and reporting. Our systematic literature review started with the planning phase, during which the need for the study was confirmed and the research protocol, which specified the research goals, research questions and review methods, was defined. A pilot search was also conducted during the planning phase in order to better define the search strings. During the conducting phase, search queries were performed and primary studies were selected and analysed based on the classification scheme. In this paper, primary studies refer to original papers that constitute this SLR.

\subsection{Research Questions}

The goal of this SLR is to discover existing research on customer involvement in CD. This leads to the following research questions:

Table 1. Research questions

\begin{tabular}{|c|c|}
\hline Research Question & Aim \\
\hline $\begin{array}{l}\text { RQ1: What is the current state-of-the-art related to } \\
\text { understanding customer involvement in CD? } \\
\text { RQ1.1 Which research methods are used? } \\
\text { RQ1.2 Which kinds of contribution have been made? } \\
\text { RQ1.3 Which kinds of research have been done? } \\
\text { RQ1.4 Which publication mediums have been used? } \\
\text { RQ1.5 What are the levels of rigor and relevance in } \\
\text { the studies? }\end{array}$ & $\begin{array}{l}\text { To provide an overview of the studies on } \\
\text { customer involvement in continuous deploy- } \\
\text { ment in the context of software intensive } \\
\text { products and services. } \\
\text { To categorize available research according to } \\
\text { research method, contribution, type, medium } \\
\text { and to assess the quality of the studies by } \\
\text { examining two perspectives: scientific rigor } \\
\text { and industrial relevance. }\end{array}$ \\
\hline $\begin{array}{l}\text { RQ2: What are the current and/or potential methods } \\
\text { and tools for obtaining and managing customer data in } \\
\text { a continuous process? } \\
\text { RQ2.1 What are the current and/or potential methods } \\
\text { and tools? } \\
\text { RQ2.2 How the data has been utilised? }\end{array}$ & $\begin{array}{l}\text { To identify the reported methods and tools for } \\
\text { collecting and managing customer-related data } \\
\text { in CD. } \\
\text { To identify the reported ways in which col- } \\
\text { lected data was applied to support relevant } \\
\text { functions in different contexts. }\end{array}$ \\
\hline $\begin{array}{l}\text { RQ3: What are the current and/or potential benefits of } \\
\text { involving the customer in CD? }\end{array}$ & $\begin{array}{l}\text { To identify the reported benefits which are } \\
\text { experienced with customer involvement in CD. }\end{array}$ \\
\hline $\begin{array}{l}\text { RQ4: What are the current and/or potential challenges } \\
\text { of involving the customer in CD? }\end{array}$ & $\begin{array}{l}\text { To identify the reported challenges which are } \\
\text { experienced with customer involvement in CD. }\end{array}$ \\
\hline
\end{tabular}




\subsection{Search}

The search terms were identified based on the research questions presented in Table 1. Afterwards, the search terms were reviewed using the guidelines created by Kitchenham and Charters [11] for populations and interventions. Our study focuses on literature that discusses customer (population) involvement in software development practices that intend to use $\mathrm{CD}$ (intervention). To increase publication coverage and ensure that we did not miss any relevant primary studies, we decided to keep the search terms broad. For this reason, we employed three different search strings for each selected database and aggregated the results based on the research questions. Each string identified keywords related to common populations and interventions as well as keywords that searched the query for a specific purpose. In Query 1, we used terms related to population, including terms associated with customer satisfaction, collaborative service design and improvement. For example the term "service design" was used because it is a methodological approach for customer involvement during the software development process. In addition to the terms related to intervention in Query 2, we searched the query for software development. Lastly, we used more specific terms about continuous software development together with terms related to intervention and population in Query 3. The following search strings were piloted:

- Query1: ("continuous deployment" OR "continuous delivery" OR "continuous improvement") AND ("customer involvement" OR "customer feedback" OR "user involvement" OR "user feedback" OR "customer satisfaction" OR "customer focus" OR "service design" OR "co-creation" OR "co-design")

- Query2: ("continuous deployment" OR "continuous delivery" OR "continuous improvement") AND ("software development")

- Query3: ("continuous software development" OR "continuous customer feedback" OR "continuous customer involvement" OR "continuous user feedback" OR "continuous user involvement")

The search was performed from April to July 2014, after the researchers reviewed several experimental searches. Additionally, an update search was performed from January to March 2015, and the results were aggregated with those of the first search. As databases, we used ACM, IEEE Xplore, ISI Web of Science, ScienceDirect, SCOPUS and Proquest. The search was performed for all fields related to information technology, including titles, abstracts and keywords. After combining all the results together and excluding the duplicates, 2429 papers had been obtained.

\subsection{Study Selection}

The primary study selection process started with 2429 papers uploaded to RefWorks ${ }^{2}$, where duplicates were automatically identified and removed. Four researchers performed a three-round screening process based on the selection criteria. The criteria for selecting the primary studies determined which studies were included or excluded in

2 https://www.refworks.com/ 
each round of the selection process. We carefully enhanced the criteria for each round so the risk of missing a relevant paper was minimised. General inclusion and exclusion criteria are listed below, and the enhanced criteria for each round can be seen in Table 2.

- General inclusion criteria: Include the paper if it is: (a conference paper, journal article, technical report, $\mathrm{PhD}$ thesis, tutorial, magazine article, opinion paper, chapter in a compilation book, e.g. conference proceedings) AND (discusses continuous customer involvement).

- General exclusion criteria: Exclude the paper if it is: not written in English, a summary, an extended abstract, a master's thesis or a whole book.

Table 2. Inclusion and exclusion criteria per round

\begin{tabular}{|c|c|c|}
\hline & Include the paper if it & Exclude the paper if it \\
\hline $\begin{array}{l}\text { Round } 1 \\
\text { Read only the title, } \\
\text { check the paper type, } \\
\text { mark your selection }\end{array}$ & $\begin{array}{l}\text { fulfils the general inclusion crite- } \\
\text { ria }\end{array}$ & fulfils the general exclusion criteria \\
\hline $\begin{array}{l}\text { Round } 2 \\
\text { Read only the ab- } \\
\text { stract and mark your } \\
\text { selection }\end{array}$ & $\begin{array}{l}\text { fulfils inclusion criteria from the } \\
\text { previous round AND is from } \\
\text { (software engineering or business } \\
\text { studies) }\end{array}$ & $\begin{array}{l}\text { fulfils exclusion criteria from the previous } \\
\text { round AND is clearly not from (software } \\
\text { engineering or business studies) }\end{array}$ \\
\hline $\begin{array}{l}\text { Round } 3 \\
\text { Read the introduc- } \\
\text { tion, results and } \\
\text { conclusion (do light } \\
\text { reading if needed) }\end{array}$ & $\begin{array}{l}\text { fulfils inclusion criteria from the } \\
\text { previous round OR is discussing } \\
\text { customer input during a software } \\
\text { development process that can be } \\
\text { related to the practice of CD }\end{array}$ & $\begin{array}{l}\text { fulfils exclusion criteria from the previous } \\
\text { round AND (does not have any customer } \\
\text { elements OR has customer elements but they } \\
\text { are not continuous OR they are not involved in } \\
\text { a software development process that can be } \\
\text { related to the practice of CD) }\end{array}$ \\
\hline
\end{tabular}

Four researchers individually marked the papers to be included, excluded or could not be decided based on each round's criteria, each paper was marked by two researchers. If both researchers marked the same paper as included or excluded, there was no conflict. If the researchers' marks were different, or if both researchers could not decide whether a paper should be included or excluded, then the paper was discussed during the conflict meetings conducted at the end of each round. In the conflict meetings, if the conflict could not be resolved by all four researchers, the paper was included in this round to be evaluated in more depth in the next round. At the end of the third round of the screening process, the researchers read all of the primary study candidates and performed a quality assessment. New papers were added to the primary study collection by performing backward snowball sampling [12] and tracking key researchers' work in the field. The paper selection process resulted in 25 primary studies, as can be seen in Figure 1. 


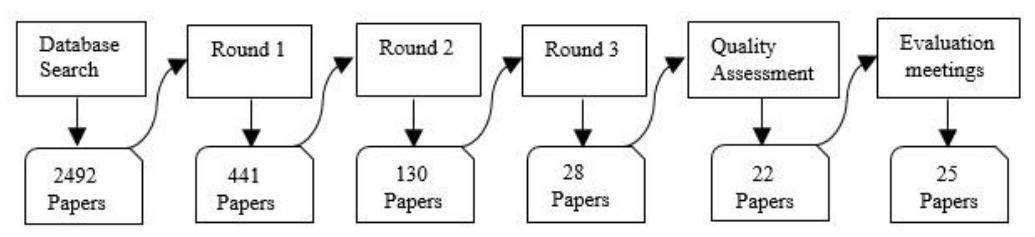

Fig. 1. Primary study selection process and number of papers

\subsection{Quality Assessment and Data Extraction}

In this SLR, we conducted the quality assessment and data extraction processes in parallel. The data extraction process began after the primary studies were uploaded to the QSR NVivo ${ }^{3}$ tool. We divided the papers into three groups and randomly assigned them to three researchers, who are the first three authors of this paper. Each researcher went through her assigned portion and coded the parts of the papers that provided answers to the research questions. A spreadsheet was used to evaluate the rigor and relevance of each study as well as other data, as proposed by Ivarsson and Gorschek [13] (see Table 3). Two perspectives, scientific rigor and industrial relevance, were considered. Scientific rigor was evaluated with three aspects: 1) context: to what degree the context is described well; 2) study design: to what degree the study design is described appropriately so that it guarantees the quality of the study; 3) validity: to what extend the validity of the study is considered and evaluated. Rigor was evaluated by using a three-point scale: strong description (1), medium description $(0.5)$ and weak description (0). Furthermore, industrial relevance was evaluated according to subject, context, scale and research method by using two values: 1 , if the aspect contributed to industrial relevance and 0 otherwise. After that, the rigor and relevance ranks for each study were summed up (e.g. if a study has strongest rigor in all 3 categories, the sum is 3 ; if has strongest relevance in all 4 categories, then the sum is 4). Both the quality assessment and data extraction processes were iterative, and after each the researchers held an evaluation meeting and reviewed all the papers.

Table 3. Data extraction sheet items

\begin{tabular}{|c|c|c|}
\hline Data item & Description & Value \\
\hline \multicolumn{3}{|l|}{ General } \\
\hline ID & unique ID number for the primary study & integer \\
\hline Title & name of the study & string \\
\hline Publication year & calendar year & integer \\
\hline $\begin{array}{l}\text { Research } \\
\text { method }\end{array}$ & $\begin{array}{l}\text { method used to conduct the research, } \\
\text { adapted by [14] }\end{array}$ & $\begin{array}{l}\text { case study, action research, survey, literature } \\
\text { review, opinion paper, experience report, not stated }\end{array}$ \\
\hline Contribution & $\begin{array}{l}\text { type of contribution of the study, adapted by } \\
{[15]}\end{array}$ & $\begin{array}{l}\text { model, theory, framework, guidelines, lessons } \\
\text { learned, advice, tool, not stated }\end{array}$ \\
\hline Research type & type of the research, adapted by $[16]^{4}$ & empirical, theoretical, both, not clear \\
\hline Medium & channel used to publish the study & $\begin{array}{l}\text { conference, journal, workshop, magazine, tutorial, } \\
\text { book chapter }\end{array}$ \\
\hline Rigor & scientific rigor, adapted by [13] & \\
\hline
\end{tabular}

3 http://www.qsrinternational.com/

4 Due to low maturity in the envisioned field of investigation, this categorization is chosen in order to see the general picture of types of the research. 


\begin{tabular}{|c|c|c|}
\hline Context & if the context is described well & 0 for weak, 0.5 for medium, 1 strong \\
\hline Study design & if the study was designed well & 0 for weak, 0.5 for medium, 1 strong \\
\hline "Validity & if the validity was discussed & 0 for weak, 0.5 for medium, 1 strong \\
\hline Relevance & industrial relevance, adapted by [13] & \\
\hline Subjects & $\begin{array}{l}\text { if subjects of the study are associated with } \\
\text { customer involvement in a real-world } \\
\text { context that could be related to the CD }\end{array}$ & 0 for no, 1 for yes \\
\hline Context & $\begin{array}{l}\text { If the study is performed in a representative } \\
\text { setting }\end{array}$ & 0 for no, 1 for yes \\
\hline Scale & $\begin{array}{l}\text { if the scale of the applications used in the } \\
\text { evaluation or conclusion is realistic, i.e. the } \\
\text { applications are industrial-scale }\end{array}$ & 0 for no, 1 for yes \\
\hline $\begin{array}{l}\text { Research } \\
\text { method }\end{array}$ & $\begin{array}{l}\text { if the research method used in the study } \\
\text { contributes to an investigation of real situa- } \\
\text { tions }\end{array}$ & 0 for no, 1 for yes \\
\hline
\end{tabular}

\subsection{Data analysis}

The extracted data was analysed, tabulated and visualised using different strategies. RQ1, where the state-of-the-art was examined, was answered using descriptive statistics based on the data extraction sheet. Following Cruzes and Dybå's recommendations [17], RQ2, RQ3 and RQ4 were examined by a thematic analysis based on the data extracted by NVivo software. We followed the approach where one researcher identified recurring themes from the extracted data. Afterwards, other researchers reviewed the themes and reconstructed the categories. The final categories can be seen in Section 3.

\section{Results and Discussion}

From the initial set of 2429 studies, 25 studies were identified as contributing to the topic of customer involvement in CD and were analysed. Due to the space limitations, detailed list of primary studies can be found online ${ }^{5}$ and the shortened list can be seen in Table 4. The results are structured according to the research questions presented in Section 2.1, followed by an overall discussion of the results.

Table 4. Primary Studies

\begin{tabular}{|c|c|c|}
\hline$\overline{I D}$ & First Author, Year & Title of the Primary Study \\
\hline$\overline{\mathrm{P} 1}$ & Arias, G., 2012 & The 7 key factors to get successful results in the IT Development projects. \\
\hline P2 & Chen, C. C., 2011 & $\begin{array}{l}\text { Discriminative effect of user influence and user responsibility on information system } \\
\text { development processes and project management. }\end{array}$ \\
\hline P3 & Claps, G. G., 2015 & $\begin{array}{l}\text { On the journey to continuous deployment: Technical and social challenges along the } \\
\text { way. }\end{array}$ \\
\hline P4 & Fabijan, A., 2015 & $\begin{array}{l}\text { Customer Feedback and Data Collection Techniques in Software R\&D: A Literature } \\
\text { Review. }\end{array}$ \\
\hline P5 & Fagerholm, F., 2014 & Building blocks for continuous experimentation. \\
\hline P6 & Ferreira, C., 2008 & $\begin{array}{l}\text { Agile systems development and stakeholder satisfaction: a South African empirical } \\
\text { study. }\end{array}$ \\
\hline P7 & Grisham, P. S., 2005 & Customer relationships and extreme programming. \\
\hline P8 & Hess, J., 2013 & $\begin{array}{l}\text { Involving users in the wild-Participatory product development in and with online } \\
\text { communities. }\end{array}$ \\
\hline P9 & Jakobi, T., 2013 & Always beta: cooperative design in the smart home. \\
\hline
\end{tabular}

5 http://www.cs.helsinki.fi/group/ese/customer_involvement_slr/primary_studies.pdf 


\begin{tabular}{|c|c|c|}
\hline P10 & Krusche, S., 2014 & Introduction of continuous delivery in multi-customer project courses. \\
\hline P11 & Krusche, S., 2014 & User feedback in mobile development. \\
\hline P12 & Labib, C., 2009 & Early development of graphical user interface (GUI) in agile methodologies (extended) \\
\hline P13 & Lee, C., 2013 & $\begin{array}{l}\text { Learning from a design experience: continuous user involvement in development of } \\
\text { aging-in-place solution for older adults. }\end{array}$ \\
\hline P14 & Maalej, W., 2009 & When users become collaborators: towards continuous and context-aware user input. \\
\hline P15 & $\begin{array}{l}\text { Mehlenbacher, B., } \\
1993\end{array}$ & $\begin{array}{l}\text { Software usability: choosing appropriate methods for evaluating online systems and } \\
\text { documentation. }\end{array}$ \\
\hline P16 & Meijer, E., 2014 & The responsive enterprise: Embracing the hacker way. \\
\hline P17 & $\begin{array}{l}\text { Muthitacharoen, A. } \\
\text { M., } 2009\end{array}$ & $\begin{array}{l}\text { Examining user involvement in continuous software development: (a case of error } \\
\text { reporting system). }\end{array}$ \\
\hline P18 & Ogonowski, C., 2013 & Designing for the living room: long-term user involvement in a living lab. \\
\hline P19 & Olsson, H. H., 2012 & $\begin{array}{l}\text { Climbing the" Stairway to Heaven"--A Multiple-Case Study Exploring Barriers in the } \\
\text { Transition from Agile Development towards Continuous Deployment of Software. }\end{array}$ \\
\hline $\mathrm{P} 20$ & Olsson, H. H., 2013 & $\begin{array}{l}\text { Towards R\&D as innovation experiment systems: A framework for moving beyond } \\
\text { Agile software development. }\end{array}$ \\
\hline $\mathrm{P} 21$ & Pagano, D., 2013 & User involvement in software evolution practice: a case study. \\
\hline $\mathrm{P} 22$ & $\begin{array}{l}\text { Poppendieck, } \\
2012\end{array}$ & n software development: A tutorial. \\
\hline $\mathrm{P} 23$ & Schneider, K., 2010 & Feedback in context: Supporting the evolution of IT-ecosystems. \\
\hline $\mathrm{P} 24$ & $\begin{array}{l}\text { Torrecilla-Salinas, } \\
\text { C. J., } 2015\end{array}$ & $\begin{array}{l}\text { Estimating, planning and managing Agile Web development projects under a value- } \\
\text { based perspective. }\end{array}$ \\
\hline P25 & Wilcox, E., 2007 & Agile development meets strategic design in the enterprise. \\
\hline
\end{tabular}

\subsection{State-of-the-Art}

Figure 2 shows that the case study was the most popular research method among the primary studies. Figure 3 shows that over half of the research (19 papers) described the lessons learned as a result of research done, provided guidelines and advice. Less than half (12 papers) of the papers presented more concrete approaches, such as a model, a tool or framework. It should be noted that some studies contributed in multiple ways. As shown in Figure 4, the majority of primary studies, 14 papers, provided empirical contributions, and only 6 papers provided theoretical contributions. Regarding publication channels, the majority (20 papers) of primary studies were published in peer-reviewed venues (including conference proceedings, journals and workshops). Figure 5 provides an overview of the distribution of articles among the publication mediums. Although some studies were published between 1993 and 2012, most of the studies were published between 2013 and 2015, as can be seen in Figure 6.

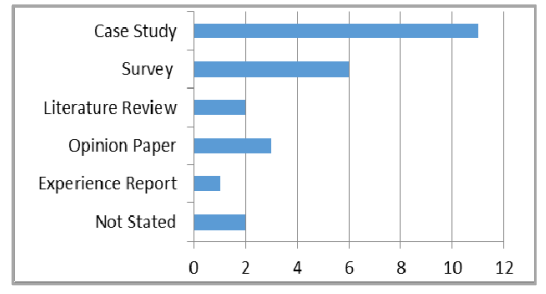

Fig. 2. State-of-the-art - research method, adapted by [14]

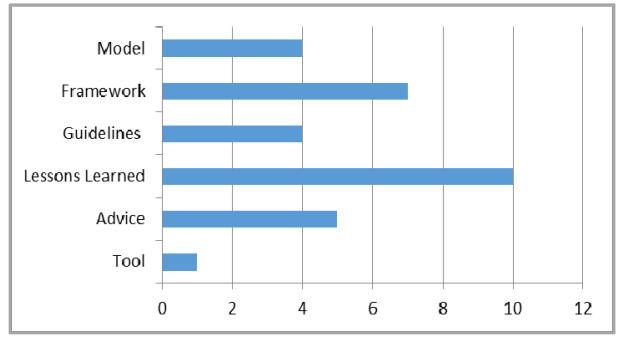

Fig. 3. State-of-the-art - research contributions, adapted by [15] 


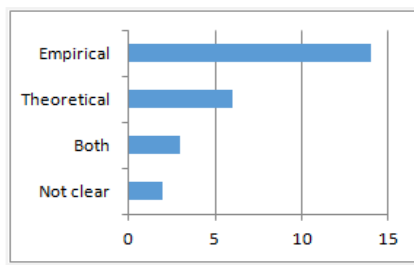

Fig. 4. State-of-the-art - research type, adapted by [16]

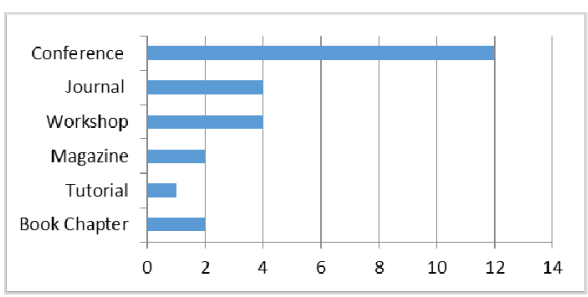

Fig. 5. State-of-the-art - publication medium

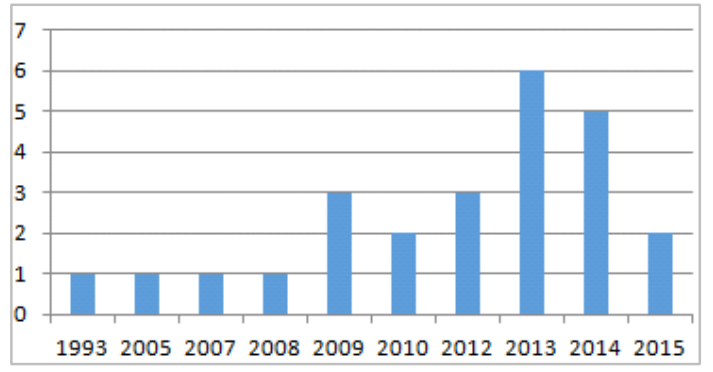

Fig. 6. State-of-the-art - publication years

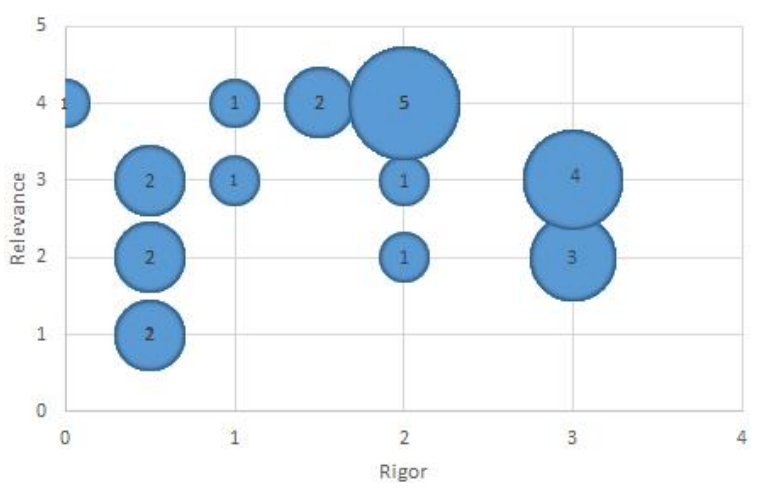

Fig. 7. Rigor and relevance overview, adapted by [13]

Figure 7 represents the number of studies in rigor and relevance scales, based on the evaluation process described in Section 2.4. In general, the majority (92\%) of the studies demonstrate strong industrial relevance (relevance $>=2$ ). Regarding scientific rigor, only $56 \%$ of the papers have a rigor higher than 2 . As a result, the primary studies regarding customer involvement in $\mathrm{CD}$ have strong industrial relevance and rela- 
tively low scientific rigor. This might be due to the fact that although there is industrial demand for the research topic, it is still new.

\subsection{Data Collection Methods and Tools}

Several methods and tools were introduced and/or used to collect customer data during CD practices, as categorised in Table 5.

Table 5. Current and/or potential data collection methods and tools

\begin{tabular}{|c|c|c|}
\hline Category & Description & $\begin{array}{l}\text { Primary } \\
\text { Studies }\end{array}$ \\
\hline $\begin{array}{l}\text { Face-to-face } \\
\text { communication }\end{array}$ & $\begin{array}{l}\text { Activities such as customer meetings, face-to-face conversations, } \\
\text { reviews, walkthroughs, discussions, interviews, customer } \\
\text { questionnaires, customer surveys (in person), videotaped sessions } \\
\text { and observations are carried out when the user and developers are } \\
\text { physically present to gather user data. }\end{array}$ & $\begin{array}{l}\text { P1, P2, P4, } \\
\text { P7, P8, P9, } \\
\text { P10, P13, } \\
\text { P14, P15, } \\
\text { P18, P23 }\end{array}$ \\
\hline $\begin{array}{l}\text { Visual } \\
\text { representations }\end{array}$ & $\begin{array}{l}\text { Creations or displays are used by the user and development team to } \\
\text { communicate about different aspects of products or services. These } \\
\text { displays can include mock-ups, prototypes, pilots, wireframes, } \\
\text { visual annotations and screenshots. }\end{array}$ & $\begin{array}{l}\text { P2, P4, P5, } \\
\text { P10, P11, } \\
\text { P12, P13, } \\
\text { P14, P15, } \\
\text { P18, P24 }\end{array}$ \\
\hline User activities & $\begin{array}{l}\text { User activities are activities and techniques that are planned and } \\
\text { carried out with two aims: (a) to provide training to the user or (b) } \\
\text { to obtain feedback about different aspects of the product or the } \\
\text { service from the user. These activities include user training, plan- } \\
\text { ning games, blitz planning, planning poker, the whole team, cus- } \\
\text { tomer boot camp, workshops, focus groups, the Wizard of Oz } \\
\text { technique, theatre sessions, software cinema, user partnering, diary } \\
\text { studies and online meetings. }\end{array}$ & $\begin{array}{l}\text { P1, P2, P4, } \\
\text { P7, P8, P13, } \\
\text { P14, P15, } \\
\text { P18, P24 }\end{array}$ \\
\hline $\begin{array}{l}\text { Experiments and } \\
\text { tests }\end{array}$ & $\begin{array}{l}\text { Experiments and tests, such as continuous experimentation and } \\
\text { A/B tests are designed to test different hypotheses with certain } \\
\text { groups of customers to obtain real-time feedback. This feedback } \\
\text { can be used to improve future experiments, design new experi- } \\
\text { ments and/or aid decision-making. }\end{array}$ & $\begin{array}{l}\mathrm{P} 3, \mathrm{P} 4, \mathrm{P} 5 \\
\mathrm{P} 14, \mathrm{P} 15 \\
\mathrm{P} 16, \mathrm{P} 17 \\
\mathrm{P} 18, \mathrm{P} 20\end{array}$ \\
\hline $\begin{array}{l}\text { Applications and } \\
\text { application } \\
\text { distribution } \\
\text { platforms }\end{array}$ & $\begin{array}{l}\text { Software solutions that either run independently, such as a feed- } \\
\text { back application, or are integrated in a large system, such as } \\
\text { plugins, are used to obtain feedback from the user. Application } \\
\text { distribution platforms are also be used to gather feedback. }\end{array}$ & $\begin{array}{l}\text { P5, P8, P10, } \\
\text { P14, P18, } \\
\text { P21, P23 }\end{array}$ \\
\hline $\begin{array}{l}\text { Co-development } \\
\text { with the user }\end{array}$ & $\begin{array}{l}\text { Placing the user in different roles, such as lead user, lead customer, } \\
\text { co-creator, co-developer and key user, is a way to gather users' } \\
\text { input about the development process. }\end{array}$ & $\begin{array}{l}\mathrm{P} 1, \mathrm{P} 8, \mathrm{P} 14, \\
\mathrm{P} 18, \mathrm{P} 19, \mathrm{P} 20\end{array}$ \\
\hline Log data & $\begin{array}{l}\text { Log data is data that has been collected from different actions by } \\
\text { the user or the system, such as user clicks, system logs, and usage } \\
\text { diaries. }\end{array}$ & $\begin{array}{l}\mathrm{P} 4, \mathrm{P} 9, \mathrm{P} 10, \\
\mathrm{P} 13, \mathrm{P} 18, \mathrm{P} 20\end{array}$ \\
\hline $\begin{array}{l}\text { User } \\
\text { communities }\end{array}$ & $\begin{array}{l}\text { User communities are groups of people that are usually connected } \\
\text { by an online platform for collaboration to generate and share ideas } \\
\text { related to a similar product or service. If the product or service } \\
\text { satisfies the overall user community, it can cause the user to pro- } \\
\text { vide efficient input about development activities. These communi- } \\
\text { ties are open source communities, open design spaces, innovation } \\
\text { communities and communities for co-design. }\end{array}$ & $\begin{array}{l}\mathrm{P} 8, \mathrm{P} 14, \mathrm{P} 17, \\
\mathrm{P} 18, \mathrm{P} 21, \mathrm{P} 25\end{array}$ \\
\hline Bug reports & $\begin{array}{l}\text { Bug reports are crash, fault or error reports sent to developers } \\
\text { demonstrating the system or product's failure to perform as ex- } \\
\text { pected under specified conditions. }\end{array}$ & $\begin{array}{l}\mathrm{P} 4, \mathrm{P} 10, \mathrm{P} 17, \\
\mathrm{P} 18, \mathrm{P} 21\end{array}$ \\
\hline
\end{tabular}




\begin{tabular}{|c|c|c|}
\hline Living labs & $\begin{array}{l}\text { Living labs are characterised by user-centric environments for } \\
\text { open innovation in which early and continuous user involvement is } \\
\text { supported. Likewise, developers are also be involved in-situ, } \\
\text { meaning that they are next to the user and receive direct feedback } \\
\text { in an action-centric real-world environment. }\end{array}$ & $\begin{array}{l}\mathrm{P} 8, \mathrm{P} 9, \mathrm{P} 14, \\
\mathrm{P} 18\end{array}$ \\
\hline $\begin{array}{l}\text { Communication } \\
\text { tools and } \\
\text { services }\end{array}$ & $\begin{array}{l}\text { Communication tools and services include various means of com- } \\
\text { munication that gather feedback from the user, such as email, } \\
\text { phones, wikis, forums, audio or video. }\end{array}$ & $\begin{array}{l}\mathrm{P} 8, \mathrm{P} 10, \mathrm{P} 18, \\
\mathrm{P} 21\end{array}$ \\
\hline Social media & $\begin{array}{l}\text { Data sources such as Twitter, Instagram and Facebook are used to } \\
\text { be in touch with the customer. }\end{array}$ & $\begin{array}{l}\text { P4, P8, P18, } \\
\text { P21 }\end{array}$ \\
\hline $\begin{array}{l}\text { Online data } \\
\text { sources }\end{array}$ & $\begin{array}{l}\text { Online ads, online surveys, in-product surveys and web polls are } \\
\text { used to receive user feedback. }\end{array}$ & $\begin{array}{l}\text { P4, P8, P17, } \\
\text { P18 }\end{array}$ \\
\hline $\begin{array}{l}\text { Integrated feed- } \\
\text { back mecha- } \\
\text { nisms }\end{array}$ & $\begin{array}{l}\text { Integrated feedback mechanisms are channels set up within the } \\
\text { system or server to support automatic transmission of feedback } \\
\text { from the user. }\end{array}$ & $\mathrm{P} 10, \mathrm{P} 21$ \\
\hline $\begin{array}{l}\text { Developers as } \\
\text { customers }\end{array}$ & $\begin{array}{l}\text { Developers sometimes assume the role of a product owner or a } \\
\text { customer. This helps them look at the development process from a } \\
\text { different perspective. }\end{array}$ & $\mathrm{P} 4, \mathrm{P} 22$ \\
\hline
\end{tabular}

Based on the categories identified above, we think that the methods and tools can be applied at different stages of software development; for example, face-to-face communication can be employed during the requirements elicitation process. Therefore, no one method or tool is better than the other. Instead, using them in combination can provide different data that improve the CD process. However, in CD process, the customer feedback collection from the deployed software should happen even near real-time or as early as possible to support design decisions on real customer usage. For example, experiments and tests are designed to test different hypotheses with certain groups of customers to obtain real-time feedback (even without users not knowing about it). In addition, customer involvement and feedback collection are important not only in the requirements elicitation process but also other stages of the development life cycle. For instance, mock-ups or prototypes can be used to validate the customer requirements and in-product surveys can reveal necessities for software evolution. Face-to-face communication, visual representations and user activities were the most popular ways of collecting customer data, perhaps because they entail high degrees of interaction with the customer, making the customer feel more involved in the process. It is also meaningful for the customer to be involved in different roles (e.g. as lead customer, co-creator, etc.) as this enables them to experience the impact of their involvement.

\subsection{Data Utilisation}

We investigated the ways in which collected customer information was/can be applied in the real-world settings to support relevant functions. These applications can be seen in Table 6 . 
Table 6. Current and/or potential data utilisation methods and ideas

\begin{tabular}{|c|c|c|}
\hline Category & Description & Primary Studies \\
\hline $\begin{array}{l}\text { Decision- } \\
\text { making }\end{array}$ & $\begin{array}{l}\text { Customer input is used for decision-making, including deciding if a } \\
\text { feedback requires a fix or if it is a request for a feature and planning } \\
\text { and prioritising tasks. }\end{array}$ & $\begin{array}{l}\mathrm{P} 2, \mathrm{P} 4, \mathrm{P} 5, \mathrm{P} 6, \mathrm{P} 8, \mathrm{P} 13, \\
\mathrm{P} 14, \mathrm{P} 16, \mathrm{P} 17, \mathrm{P} 18, \mathrm{P} 20 \\
\mathrm{P} 21, \mathrm{P} 22, \mathrm{P} 25\end{array}$ \\
\hline $\begin{array}{l}\text { Learning } \\
\text { about the } \\
\text { user }\end{array}$ & $\begin{array}{l}\text { User input is used to better understand the user through, for example, } \\
\text { user satisfaction and learning usage/behaviour patterns, such as } \\
\text { which features are used more often than others and which mistakes } \\
\text { are made often. }\end{array}$ & $\begin{array}{l}\mathrm{P} 4, \mathrm{P} 5, \mathrm{P} 8, \mathrm{P} 14, \mathrm{P} 17, \mathrm{P} 18 \\
\mathrm{P} 19, \mathrm{P} 20, \mathrm{P} 21, \mathrm{P} 22, \mathrm{P} 23 \\
\mathrm{P} 25\end{array}$ \\
\hline Improvement & $\begin{array}{l}\text { The service or the product is improved (functionality and quality) in } \\
\text { the long term based on the collected data. New functionalities are } \\
\text { added to the existing product based on customer input. }\end{array}$ & $\begin{array}{l}\text { P4, P5, P6, P10, P17, P18, } \\
\text { P20, P22, P23 }\end{array}$ \\
\hline $\begin{array}{l}\text { Assessing the } \\
\text { service or the } \\
\text { product }\end{array}$ & $\begin{array}{l}\text { Software companies use the collected data to assess a service or } \\
\text { product based on, for example, acceptance of the product and prod- } \\
\text { uct-market fit. }\end{array}$ & $\begin{array}{l}\mathrm{P} 4, \mathrm{P} 5, \mathrm{P} 8, \mathrm{P} 18, \mathrm{P} 20, \mathrm{P} 21, \\
\mathrm{P} 23\end{array}$ \\
\hline Fast reaction & $\begin{array}{l}\text { Developers quickly react to user input, for instance, to fix major } \\
\text { bugs, learn more about the problems and obtain support from user } \\
\text { communities. }\end{array}$ & $\mathrm{P} 4, \mathrm{P} 6, \mathrm{P} 10, \mathrm{P} 17, \mathrm{P} 18, \mathrm{P} 25$ \\
\hline
\end{tabular}

We notice that the most frequently reported way of using the customer data is to use it to support decision-making. Customer input should assist both business and technical decision-making, for instance for roadmapping and requirement prioritization processes, and guide all R\&D efforts. User communities can also help with the decision-making process offering their wisdom [18]. The collected data can be also used to learn more about the users. For instance, usage patterns can be discovered to track success or failures made with a product [P25]. Similarly, A/B testing can tell about which version release is preferable by the users [P20] and the user feedback can throw light on user satisfaction [P8]. Based on what is learnt, system or product can be improved both in functionality and quality. Also, developers can react to the collected data fast, especially when critical problems need to be fixed.

\subsection{Benefits}

The benefits of continuously involving the customer in the development process were frequently addressed by the primary studies, as can be seen in Table 7 .

Table 7. Current and/or potential benefits of involving the customer in CD

\begin{tabular}{|c|c|c|}
\hline Benefit & Description & Primary Studies \\
\hline $\begin{array}{l}\text { Continuous } \\
\text { learning and } \\
\text { improvement }\end{array}$ & $\begin{array}{l}\text { Customer data is used to eliminate any work that does not } \\
\text { bring value to the customer or improve the system or product } \\
\text { (e.g. software quality improvement, higher user satisfaction). } \\
\text { Thus, the decision-making process is based on sound evidence } \\
\text { rather than guesswork. }\end{array}$ & $\begin{array}{l}\text { P2, P4, P5, P6, P7, } \\
\text { P8, P13, P16, P18, } \\
\text { P19, P20, P21, P22, } \\
\text { P23, P25 }\end{array}$ \\
\hline $\begin{array}{l}\text { First-hand user } \\
\text { needs }\end{array}$ & $\begin{array}{l}\text { Gathering first-hand user needs and direct feedback helps } \\
\text { developers reduce the gap between user expectations and } \\
\text { implementation. It also helps developers validate their } \\
\text { understandings of the user requirements. }\end{array}$ & $\begin{array}{l}\mathrm{P} 2, \mathrm{P} 6, \mathrm{P} 7, \mathrm{P} 9, \mathrm{P} 10 \\
\mathrm{P} 11, \mathrm{P} 13, \mathrm{P} 18, \mathrm{P} 19 \\
\mathrm{P} 20, \mathrm{P} 24\end{array}$ \\
\hline $\begin{array}{l}\text { Shorter } \\
\text { feedback loop, } \\
\text { faster reaction }\end{array}$ & $\begin{array}{l}\text { A shorter feedback cycle makes it possible to quickly learn } \\
\text { from the user and increase the speed of decision-making, such } \\
\text { as by taking corrective actions during product development. }\end{array}$ & $\begin{array}{l}\text { P3, P4, P6, P10, } \\
\text { P12, P16, P17, P19, } \\
\text { P20, P22,P25 }\end{array}$ \\
\hline $\begin{array}{l}\text { Advertisement } \\
\text { and time to }\end{array}$ & $\begin{array}{l}\text { Customer input is useful in advertising and marketing strate- } \\
\text { gies for the products or services. As the feedback is received }\end{array}$ & $\begin{array}{l}\mathrm{P} 3, \mathrm{P} 5, \mathrm{P} 8, \mathrm{P} 13, \\
\mathrm{P} 16, \mathrm{P} 18, \mathrm{P} 19, \mathrm{P} 21\end{array}$ \\
\hline
\end{tabular}




\begin{tabular}{l|l|l}
\hline $\begin{array}{l}\text { market } \\
\text { User } \\
\text { motivation }\end{array}$ & $\begin{array}{l}\text { from the market, a product-market fit can be reached sooner. } \\
\text { Cooperation between the user and developers motivates the } \\
\text { user to co-develop and participate more actively in the devel- } \\
\text { opment process. Also, user motivation is driven by the likely } \\
\text { benefit of providing input. Similarly, giving the customer } \\
\text { some control over decision-making increases overall satisfac- } \\
\text { tion. }\end{array}$ & $\begin{array}{l}\mathrm{P} 24, \mathrm{P} 13, \mathrm{P} 2, \mathrm{P} 6, \mathrm{P} 20, \mathrm{P} 17, \mathrm{P} 23, \\
\mathrm{P} 7, \mathrm{P} 18\end{array}$ \\
$\begin{array}{l}\text { Communica- } \\
\text { tion and trust }\end{array}$ & $\begin{array}{l}\text { Building long-term relationships and trust with customers } \\
\text { helps to improve communication. In some cases, receiving } \\
\text { useful feedback might be possible only after the long-term } \\
\text { establishment of trust. }\end{array}$ & $\mathrm{P} 13, \mathrm{P} 18, \mathrm{P} 25$ \\
\hline $\begin{array}{l}\text { New products } \\
\text { and features }\end{array}$ & $\begin{array}{l}\text { Input from the customer shapes the product roadmap and helps } \\
\text { developers create new, innovative features and improvements. }\end{array}$ & $\begin{array}{l}\mathrm{P} 5, \mathrm{P} 13, \mathrm{P} 18, \mathrm{P} 20, \\
\mathrm{P} 21\end{array}$ \\
$\begin{array}{l}\text { User experi- } \\
\text { ence and us- } \\
\text { ability }\end{array}$ & $\begin{array}{l}\text { Involving the customer in the development process makes the } \\
\text { user more experienced with the product or the service. It also } \\
\text { provides ease for usability testing. }\end{array}$ & $\mathrm{P} 5, \mathrm{P} 9, \mathrm{P} 11, \mathrm{P} 18$ \\
\hline
\end{tabular}

Based on the frequencies of the primary studies in each category we see that involving the customer in $\mathrm{CD}$ practices seems to be beneficial. Building a reliable relationship with the customer eases communication and motivates them to be part of the development process. As RE research already addresses, the requirement elicitation process can be operated directly through input from first-hand users. Besides, CD enables shorter user feedback loops, which enables faster reactions when decisions must be made. Customer input can also be used as a means for innovation [P20]. The collected data is used to continuously learn more about the customer, which can be used to update the product roadmap and improve the product. The time to market can be optimised through early customer involvement, which is especially crucial for start-ups, for which budget is a primary concern [P5]. Through continuous involvement in development activities, the customer will be more experienced and provide efficient feedback and usability data.

\subsection{Challenges}

The current and/or potential challenges of involving the customer in CD are outlined in Table 8.

Table 8. Current and/or potential challenges of involving the customer in CD

\begin{tabular}{|c|c|c|}
\hline Challenge & Description & $\begin{array}{l}\text { Primary } \\
\text { Studies }\end{array}$ \\
\hline $\begin{array}{l}\text { Customer } \\
\text { perception and } \\
\text { behaviour }\end{array}$ & $\begin{array}{l}\text { Customers' perceptions of their involvement in development are } \\
\text { challenging. They might feel disturbed or interrupted from their on- } \\
\text { going work (e.g. by product surveys or pop-up windows), and they } \\
\text { might give negative or insufficient feedback. The customer can also } \\
\text { be unsure about what they want and how to express it. }\end{array}$ & $\begin{array}{l}\text { P2, P4, P7, } \\
\text { P8, P9, P14, } \\
\text { P17, P18, } \\
\text { P20, P23 }\end{array}$ \\
\hline Communication & $\begin{array}{l}\text { Communication with the customer portrays difficulties, such as estab- } \\
\text { lishing trust before collaboration and choosing the right form of } \\
\text { communication strategy. Also, managing the process, such as by } \\
\text { dealing with conflicts, with different stakeholders is challenging. }\end{array}$ & $\begin{array}{l}\text { P1, P2, P8, } \\
\text { P9, P10, } \\
\text { P14, P18, } \\
\text { P21, P24 }\end{array}$ \\
\hline $\begin{array}{l}\text { Data } \\
\text { management }\end{array}$ & $\begin{array}{l}\text { The customer-related data collection process and analysis of the data } \\
\text { reveal several challenges. For example, the internal verification loop } \\
\text { of the collected data has to be short and systematic, and feedback }\end{array}$ & $\begin{array}{l}\text { P3, P8, P14, } \\
\text { P19, P21, } \\
\text { P23 }\end{array}$ \\
\hline
\end{tabular}




\begin{tabular}{|c|c|c|}
\hline & $\begin{array}{l}\text { should be coming from the right channel. Similarly, the data analysis } \\
\text { process requires high effort to, for example, work with data with noise } \\
\text { in it, eliminate human factors such as subjectivity or prioritise tasks. }\end{array}$ & \\
\hline $\begin{array}{l}\text { Setting the } \\
\text { scenes }\end{array}$ & $\begin{array}{l}\text { Preparing and receiving the customer input is time-consuming. For } \\
\text { example, creating detailed feedback might be challenging due to a } \\
\text { lack of time, and organising workshops, questionnaires, interviews, } \\
\text { site visits or personal interactions might be expensive and laborious. } \\
\text { Also, different data collection techniques bring different difficulties; } \\
\text { for example, a theatre session requires sophisticated technology at a } \\
\text { special location. Sometimes it might be necessary to educate the } \\
\text { customer about a common, helpful way of providing feedback. }\end{array}$ & $\begin{array}{l}\text { P4, P17, } \\
\text { P18, P21, } \\
\text { P23 }\end{array}$ \\
\hline Transparency & $\begin{array}{l}\text { Transparency in data, process and feedback affect users' intention to } \\
\text { provide input. Limited or no transparency demotivates users to pro- } \\
\text { vide feedback. However, too much transparency causes customers to } \\
\text { interfere with developers' work. Also, due to high visibility, failures } \\
\text { might be too visible to customers. }\end{array}$ & $\begin{array}{l}\text { P3, P7, P17, } \\
\text { P18, P19 }\end{array}$ \\
\hline $\begin{array}{l}\text { Updates, new } \\
\text { features and } \\
\text { products }\end{array}$ & Customers might not realise or welcome changes. & $\begin{array}{l}\mathrm{P} 3, \mathrm{P} 7, \mathrm{P} 18, \\
\mathrm{P} 19\end{array}$ \\
\hline $\begin{array}{l}\text { Customer } \\
\text { profile }\end{array}$ & $\begin{array}{l}\text { The needs of different user groups might diverge and change in dif- } \\
\text { ferent contexts. Establishing a customer sample group where all } \\
\text { possible types of users are represented is challenging. Also, the cus- } \\
\text { tomer's level of competence, experience, knowledge and/or reliability } \\
\text { influences the success of customer involvement. }\end{array}$ & P7, P18, P23 \\
\hline $\begin{array}{l}\text { Experiments } \\
\text { and } \mathrm{A} / \mathrm{B} \text { testing }\end{array}$ & $\begin{array}{l}\text { The customer might not want to be a part of an experiment or they } \\
\text { might not welcome partially developed functionality. Moreover, } \\
\text { conducting several experiments in parallel and interpreting the results } \\
\text { are challenging. Determining where to start to experiment with the } \\
\text { customer is another challenge. }\end{array}$ & $\mathrm{P} 4, \mathrm{P} 5, \mathrm{P} 20$ \\
\hline $\begin{array}{l}\text { Sales and } \\
\text { suppliers }\end{array}$ & $\begin{array}{l}\text { Sometimes direct user data might not be accessible due to intermedi- } \\
\text { aries, such as when a company does not sell products directly to end } \\
\text { users. From the suppliers' point of view, they might not be interested } \\
\text { in collecting customer feedback after selling a product or a service. }\end{array}$ & P5, P19, P23 \\
\hline
\end{tabular}

According to the reported challenges, we draw the inference that establishing a trustworthy relationship with customers and communicating with the right channels are often found as challenging. For instance, through face-to-face interactions, customer input can be received directly. However, it is not always feasible due to, for instance, time constraints or intermediaries in the supply chain. In addition, conflicts can occur during the communication with the customer, especially when there are many stakeholders involved. On the other hand, the customers might feel disturbed by being involved in a development activity or they might not welcome any changes, such as being involved in experiments and receiving new feature updates. There is also a risk of diminishing customers' commitment if they feel that the provided feedback is not useful. Also, misinterpreting the roles and development activities might be a challenge. For example, the customer might perceive the developers as a help desk service [P9] or they might neglect context information when providing feedback [P14]. Likewise, the life cycle of customer data-collection, analysis and return to the customer if needed - poses a number of difficulties. Maalej et al. [P14] states that user input and feedback mechanisms in software systems usually follow an ad-hoc approach, if they exist at all. A systematic mechanism should provide a short internal verification loop for the collected data and ensure that data is distributed to the right 
parties for the analysis [P3], [P21] Unfortunately, user data might be also received from the wrong channels, lack important information or include irrelevant information [P14], [P21]. Moreover, especially when manual data analysis is required, human factors, such as analysts' subjectivity, can be a concern [P14]. Data analysis and decision-making based on the collected data can require much effort due to these difficulties. Lastly, preparing the necessary infrastructure for both continuous (e.g. establishing an integrated feedback mechanism) or event-based (e.g. conducting a theatre session) customer data collection tools and methods can be expensive and timeconsuming.

In summary, we remark that the existing studies illustrate that the customer can be involved in different stages of software development: pre-deployment (e.g. requirements elicitation), during deployment and after deployment (e.g. software evolution). Many benefits and a number of current or potential challenges of customer involvement in CD were addressed in the primary studies. Various methods and tools that can be used to involve customers revealed that customers can intentionally and actively participate in development activities such as user studies, and that they can passively participate in development, such as when user clicks are counted. One fundamental finding was that the communication and relationship with the customer shapes the customer's involvement. While short-term user involvement is sometimes needed, such as for questionnaires, long-term user involvement can be also necessary, such as for living labs. The primary studies indicate that collected customer data with CD can be utilised in different ways. However, there is need for new empirical studies in reallife contexts so that data utilisation methods become more factual rather than being hypothetical.

\section{$4 \quad$ Limitations}

Researcher bias might be a threat during the primary study selection rounds, data extraction and analysis. Threats to the identification of primary studies were mitigated with up-front definitions of the inclusion/exclusion criteria. In addition, the research protocol was reviewed and refined by external supervisors. However, the scope of this study covers not only customer input in $\mathrm{CD}$ but also the concepts or techniques for involving the customer in a software development process that can be related to CD. For this reason, the researchers had to make judgments about the papers that did not discuss direct implementation of CD. In order to mitigate this limitation, every paper had to be reviewed by at least two researchers, who had to reach a consensus. Furthermore, a number of discussion meetings were held to examine the data analysis steps. There might be difficulties regarding the generalisation of this study's results. Due to the novelty of the field, the existing knowledge could lead to more generalisable results when the field is strengthened by further research. 


\section{$5 \quad$ Conclusions and Future Work}

The objective of this systematic literature review was to summarise the state-ofthe-art on customer involvement in $\mathrm{CD}$, including its benefits, challenges, methods and tools. Based on 25 primary studies, we remark that customer involvement in CD is gaining attention within the software industry. We found that the scientific rigor of the studies was lower than their industrial relevance, which could indicate that the field has the potential for future discoveries. In general, customer input enhances CD activities and benefits both developers and end users. For instance, instant feedback, continuous learning, shorter time to market and improved customer satisfaction are some of the perceived benefits. We identified a number of challenges that could block customer input during development activities, such as customer misperception, customers' unwillingness to receive continuous updates, forming the right feedback methods, determining from whom and in which format the feedback should be collected. A variety of methods and tools can be used to collect and manage customer data, and the collected customer data can be utilised in several ways.

Despite the industrial demand, we identified a gap between the advantages of involving the customer in $\mathrm{CD}$ and the real-world utilisation of existing knowledge. The benefits of customer input in $\mathrm{CD}$ and the methods and tools that were used are well addressed in the primary studies, but there is less evidence on their implications. How customer involvement should be coordinated and managed still needs to be determined. However it is clear that customer involvement in CD needs an innovative and experimental organisational culture where fail fast, fail often ${ }^{6}$ is seen as an opportunity to learn and make corrective actions. Besides, RE research can enlighten CD studies with it is established body of knowledge. Correspondingly, the increasing demand on $\mathrm{CD}$ and novel approaches of costumer involvement in the field can provide new insights into RE research. For example, continuous experimentation approach can innovate requirements elicitation activities. For future work, we are interested in investigating how a customer involvement model could optimise data collection methods and tools for specific cases. Likewise, efforts should be made to negate the current challenges. Performing new case studies in collaboration with the software industry could reveal information about such countermeasures.

Acknowledgments. This work was supported by TEKEs as part of the Need for Speed project of DIGILE (Finnish Strategic Centre for Science, Technology and Innovation in the field of ICT and digital business).

\section{References}

1. Järvinen, J., Huomo, T., Mikkonen, T., Tyrväinen, P.: From Agile Software Development to Mercury Business. In Software Business. Towards Continuous Value Delivery (pp. 5871). Springer International Publishing, Paphos, Cyprus (2014)

\footnotetext{
${ }^{6} \mathrm{http} / / /$ theleanstartup.com/principles
} 
2. Laage-Hellman, J., Lind, F., Perna, A.: Customer Involvement in Product Development: An Industrial Network Perspective. Journal of Business-to-Business Marketing, 21(4), 257-276 (2014)

3. Wiegers, K.: Software Requirements. Second Edition Microsoft Press (2003)

4. Barney, S., Aurum, A., \& Wohlin, C.: A product management challenge: Creating software product value through requirements selection. Journal of Systems Architecture, 54(6), 576-593 (2008)

5. Highsmith, J.: Agile Project Management: Creating Innovative Products. Addison-Wesley Professional, New York (2009)

6. Sauvola, T., Lwakatare, L. E., Karvonen, T., Kuvaja, P., Holmstrom Olsson, H., Bosch, J.: Towards Customer-Centric Software Development, A Multiple-Case Study. In $41^{\text {st }}$ Euromicro Conferens on Software Engineering and Advanced Applications (SEAA) Portugal (2015)

7. Fabijan, A., Olsson, H. H., Bosch, J.: Customer Feedback and Data Collection Techniques in Software R\&D: A Literature Review. In Software Business (pp. 139-153). Springer International Publishing (2015)

8. Olsson, H. H., Alahyari, H., Bosch, J.: Climbing the" Stairway to Heaven"--A MultipleCase Study Exploring Barriers in the Transition from Agile Development towards Continuous Deployment of Software. In $38^{\text {th }}$ Conference on Software Engineering and Advanced Applications (SEAA), pp. 392-399, IEEE (2012)

9. Mäntylä, MV., Adams, B., Khomh, F., Engström, E., Petersen, K.: On rapid releases and software testing: a case study and a semi-systematic literature review. J. Empirical Software Engineering, vol. 20, issue 5, pp 1384-1425, (2014)

10. Abelein, U., Peach, B.: Understanding the influence of user participation and involvement on system success - A systematic mapping study. J. Empirical Software Engineering, vol.20, pp. 28-81, (2013)

11. Kitchenham, B., Charters, S.: Guidelines for performing systematic literature reviews in software engineering. EBSE Technical Report (2007)

12. Wohlin, C.: Guidelines for snowballing in systematic literature studies and a replication in software engineering. In: Proceedings of the 18th International Conference on Evaluation and Assessment in Software Engineering, New York (2014)

13. Ivarsson, M., Gorschek, T.: A method for evaluating rigor and industrial relevance of technology evaluations. Empirical Software Engineering 16(3):365-395 (2011)

14. Unterkalmsteiner, M., Gorschek, T., Cheng, CK., Permadi, RB., Feldt, R.: Evaluation and measurement of software process improvement-a systematic literature review. IEEE Transactions on Software Engineering 38(2):398-424 (2012)

15. Paternoster, N., Giardino, C., Unterkalmsteiner, M., Gorschek, T., Abrahamsson, P.: Software development in startup companies: a systematic mapping study. Information and Software Technology 56(10):1200-1218 (2012)

16. Kitchenham, B.: What's up with software metrics?-a preliminary mapping study. J. Systems and Software 83(1):37-51 (2010)

17. Cruzes, Daniela S., and Tore Dybå. "Recommended steps for thematic synthesis in software engineering." In Empirical Software Engineering and Measurement (ESEM), 2011 International Symposium on, pp. 275-284. IEEE (2011)

18. Hess, J., Wan, L., Ley, B. and Wulf, V.: In-situ everywhere: a qualitative feedback infrastructure for cross platform home-IT. In Proceedings of the 10th European conference on Interactive tv and video, pp. 75-78, ACM (2012) 